Tropical Journal of Pharmaceutical Research November 2014; 13 (11): 1837-1843

ISSN: $1596-5996$ (print); 1596-9827 (electronic)

(C) Pharmacotherapy Group, Faculty of Pharmacy, University of Benin, Benin City, 300001 Nigeria.

All rights reserved.

Available online at http://www.tjpr.org

Original Research Article

http://dx.doi.org/10.4314/tjpr.v13i11.10

\title{
Extract of Zanthoxylum bungeanum Maxim Seed Oil Reduces Hyperlipidemia in Hamsters Fed High-Fat Diet via Activation of Peroxisome Proliferator-Activated Receptor Y
}

\author{
Gang Chen ${ }^{1,2,3}$, Xue Gao ${ }^{2,3}$, Kong-Shu Zhen ${ }^{2,3}$, Zhong-Yi Yin ${ }^{2,3}$ and Xu-Xu \\ Zheng ${ }^{2,3 *}$ \\ ${ }^{1}$ School of Environmental and Biological Engineering, ${ }^{2}$ Chongqing Key Laboratory of Nature Medicine Research, ${ }^{3}$ Chongqing \\ Key Laboratory of Catalysis and Functional Organic Molecules, Chongqing Technology and Business University, Chongqing \\ 400067, China
}

*For correspondence: Email: zxx_chem@hotmail.com; Tel: (+86)-23-6276-8012; Fax: (+86)-23-6276-9652

Revised accepted: 16 September 2014

\begin{abstract}
Purpose: To investigate the anti-hyperlipidaemic effect of extract of Zanthoxylum bungeanum Maxim. seed oil (EZSO) on high-fat diet (HFD)-induced hyperlipidemic hamsters.

Methods: Following feeding with HFD for 30 days, hyperlipidemic hamsters were intragastrically treated with EZSO for 60 days. Serum levels of triglyceride (TG), total cholesterol (TC), low-density-lipoproteincholesterol (LDL-C), nitric oxide (NO) and malondialdehyde (MDA) were analyzed. Protein expression and location of peroxisome proliferator-activated receptor $y$ (PPARY) in liver were determined by Western blot and immunohistochemical assays, respectively.

Results: EZSO at 5 and $10 \mathrm{~g} / \mathrm{kg}$ significantly reduced levels of TG by 26 and $23 \%(p<0.05)$, TC by 19 $\%(p<0.01)$ and $13 \%(p<0.01)$, LDL-C by $18 \%(p<0.05)$ and $21 \%(p<0.01)$, NO by $15 \%(p<$ $0.01)$ and $31 \%(p<0.01)$, and MDA by $16 \%(p<0.05)$ and $30 \%(p<0.01)$, respectively, in serum of hyperlipidemic hamsters. However, EZSO did not show significant effect on HDL-C level in serum. Furthermore, EZSO at 5 and $10 \mathrm{~g} / \mathrm{kg}$ markedly promoted protein expression of PPARY by $71 \%$ ( $p<$ $0.05)$ and $102 \%(p<0.01)$ in liver tissue of hyperlipidemic hamsters. EZSO also notably increased the content of PPARY protein in the nucleus of liver cells of hyperlipidemic hamsters.

Conclusion: These findings suggest that EZSO can reduce hyperlipidemia and improve oxidative stress in hyperlipidemic hamsters through activation of PPARY, and that EZSO is a promising novel hypolipidemic health product.
\end{abstract}

Keywords: Zanthoxylum bungeanum, Peroxisome proliferator activated receptor $\gamma$, Hyperlipidemia, Hamster, High-fat diet

Tropical Journal of Pharmaceutical Research is indexed by Science Citation Index (SciSearch), Scopus, International Pharmaceutical Abstract, Chemical Abstracts, Embase, Index Copernicus, EBSCO, African Index Medicus, JournalSeek, Journal Citation Reports/Science Edition, Directory of Open Access Journals (DOAJ), African Journal Online, Bioline International, Open-J-Gate and Pharmacy Abstracts

\section{INTRODUCTION}

Coronary heart disease (CHD) is the leading cause of death and a major economic burden for the health care system of the developed countries all over the world. Preventing the occurrence of $\mathrm{CHD}$ with dietetic interventions is a promising strategy that has attracted a lot of research attention [1].

There is a great number of scientific evidence from human trials that $n-3$ polyunsaturated fatty acids (PUFAs) from fish or fish oil supplements include eicosapentaenoic acid (EPA) and docosahexaenoic acid (DHA) can significantly 
reduce risk factors for heart disease [2,3]. For alpha-linolenic acid (ALA), the relation to cardiovascular health is contradictory. Some evidence has been demonstrated that dietary ALA has significant cardio-protective effects [4]. However, another study found that most cardiovascular risk markers, including triglyceride (TG), total cholesterol (TC) and low-densitylipoprotein-cholesterol (LDL-C), did not appear to be affected after treatment with ALA [5]. Further researches in human and animal are both needed to clarify the cardioprotective efficacy of ALA.

Peroxisome proliferator-activated receptor $\mathrm{Y}$ (PPARy) is a nuclear receptor and acts as intracellular lipid and glucose sensor to regulate lipid and lipoprotein metabolism, glucose homoeostasis and inflammatory response [6]. The n-3PUFAs are potent activators of PPARy [7]. Thus, dietary supplementation with ALA or EPA plus DHA should induce expression of key proteins involved in cardiac lipid and lipoprotein metabolism through activating PPARY [8].

In the present study, we investigated the effect of extract of Zanthoxylum bungeanum Maxim. seed oil (EZSO), which is rich in ALA, on serum lipid level, oxidation status and underlying mechanism in hyperlipidemic hamsters. These findings may provide insight into the cardioprotective effect of EZSO and help guide the exploration of utilization of Zanthoxylum bungeanum Maxim. seeds.

\section{EXPERIMENTAL}

\section{EZSO preparation}

Zanthoxylum bungeanum Maxim. was purchased from Hangcheng Xiongdi Pepper Co., Ltd. (Shangxi, China) and was identified by Dr. Jifen Zhang, College of Pharmaceutical Sciences, Southwest University (Chongqing, China). It was authenticated using thin-layer chromatography with reference to methods recommended by the Chinese Pharmacopoeia (Chinese Pharmacopoeia, 2010). A voucher specimen number 2012-112 was deposited at the Herbarium of the Chongqing Key Laboratory of Nature Medicine Research, Chongqing Technology and Business University. EZSO was prepared and its compositions analyzed as described elsewhere [9].

\section{Animals and high-fat diet}

Male golden Syrian hamsters weighing 100-120 $\mathrm{g}$ were purchased from Chinese Academy of
Sciences (Beijing, China). All hamsters were housed in a temperature-controlled room $(23 \pm 2$ ${ }^{\circ} \mathrm{C}$ ) under a light/dark cycle with lights on from 7:00 am to 7:00 pm. They were allowed food and water ad libitum. The animals were adapted to experiment environment for 1 week before experiments were carried out. All animal procedures were approved by the Ethical Committee in Animal Research of Chongqing Technology and Business University (Ethics No. 2011-3-19/CTBU). The high-fat diets (HFD) were purchased from Vital River Laboratories (Beijing, China). The diet contained $10 \%$ fat, $1 \%$ cholesterol, $10 \%$ egg yolk powder, $0.2 \%$ sodium cholate.

\section{Animal groups and treatment}

Hamsters were fed on HFD for 30 days to develop hyperlipidemia. Hyperlipidemic hamsters were randomly divided into six groups with 10 hamsters in each group: (1) Control group; (2) Hyperlipidemia (HPL) group; (3) Simvastatin (SIM, Hangzhou Merck Sharp \& Dohme Pharmaceutical Co., Ltd., China); (4) $2.5 \mathrm{~g} / \mathrm{kg}$ EZSO group; (5) $5 \mathrm{~g} / \mathrm{kg}$ EZSO group; (6) $10 \mathrm{~g} / \mathrm{kg}$ EZSO group. Hamsters of groups 2 to 6 were fed on HFD during treatment. There were no significant differences in TG levels among groups 2 to 6 before treatment. Hamsters in groups 3, 4, 5 and 6 were intragastrically treated with SIM or EZSO once a day. Hamsters in groups 1 and 2 were intragastrically treated with an equal volume of saline once a day. All the hamsters received treatment for 60 days.

\section{Biochemical analysis}

Hamsters were fasted for $12 \mathrm{~h}$ and sacrificed under anesthesia. Blood was collected from hearts and serum was obtained by centrifuge at $3000 \mathrm{rpm}$ for $20 \mathrm{~min}$ after blood coagulated. The serum was kept at $-20{ }^{\circ} \mathrm{C}$ until analysis. TG, TC, HDL-C, LDL-C, NO and MDA levels in serum were determined using commercial kits (Nanjing Jiancheng Bioengineering Institute, Nanjing, China). Assays were performed according to the manufacturer's instructions.

\section{Immunohistochemical assay}

The liver of hamsters was removed and fixed in 4 $\%$ paraformaldehyde for $24 \mathrm{~h}$ at $4{ }^{\circ} \mathrm{C}$. The tissues were embedded in paraffin, then serial paraffin sections $(5 \mu \mathrm{m})$ were stained using a two-step polymer (non-biotin) detection kit (GBI Labs, USA). The slides were de-paraffinized and blocked for 10 min with $3 \%$ hydrogen peroxide at room temperature. Antigen retrieval with Tris/EDTA buffer (10 mM Tris-HCl, 1 mM EDTA, 
$0.05 \%$ Tween 20, pH 9.0) was performed by microwave for $10 \mathrm{~min}$. The sections were incubated with rabbit polyclonal PPAR $\gamma$ (Santa Cruz, USA) overnight at $4{ }^{\circ} \mathrm{C}$ with dilution of 1:100. After washing in TBS $(0.5 \mathrm{M}$ Tris- $\mathrm{HCl}, 0.15$ $\mathrm{M} \mathrm{NaCl}, \mathrm{pH}$ 7.6), the sections were incubated with horseradish peroxidase-conjugated goat anti-rabbit lgG for 30 min at room temperature. After washing in TBS, the complex was visualized using 3, 3'-diaminobenzidine for 5 minutes. The sections were counterstained with hematoxylin and observed under alight microscope to calculate the number of positive-stained cells PPARg $^{+}$cells) per area $(\cdot 100)$.

\section{Western blot assay}

Frozen liver tissue was homogenized in RIPA lysis buffer ( $50 \mathrm{mM}$ Tris- $\mathrm{HCl}, 150 \mathrm{mM} \mathrm{NaCl}, 1 \%$ NP-40, $0.5 \%$ sodium deoxycholate, $0.1 \%$ SDS, $\mathrm{pH}$ 7.6) and EDTA-free protease inhibitor cocktail (Roche, Switzerland). Equal amounts of protein samples were separated by SDS-PAGE electrophoresis and transferred onto PVDF membranes. After blocked with $5 \%$ defatting milk in TBST buffer $(10 \mathrm{mM}$ Tris- $\mathrm{HCl}, 150 \mathrm{mM}$ $\mathrm{NaCl}, 0.1 \%$ Tween 20, $\mathrm{pH} 7.6$ ) for $1 \mathrm{~h}$ at room temperature, PVDF membranes were incubated with anti-PPAR - (Santa Cruz, USA) or anti- $\beta$ actin antibody at $4{ }^{\circ} \mathrm{C}$ overnight. Then the membranes were incubated for $1 \mathrm{~h}$ at room temperature with appropriate HRP-conjugated secondary antibody. The protein bands were detected with enhanced chemiluminescence reagents (Milipore, USA). Chemiluminescent signals were detected and analyzed using the ChemiDoc XRS imaging system (Bio-Rad, USA).

\section{Statistical analysis}

All data were presented as mean \pm standard error (SEM). To analyze immunohistochemical data, Mann-Whitney $U$ test was used. Statistical comparison of other parameters was evaluated by ANOVA using SPSS 16 software. Results were considered significant at $p<0.05$.

\section{RESULTS}

\section{Effects of EZSO on TG, TC, LDL-C and HDL-C levels in serum}

Serum levels of TG, TC, LDL-C and HDL-C of HPL group hamsters significantly increased after 30 days on HFD relatively to those of Control group hamsters (all $p<0.001$ ). Doses of $5 \mathrm{~g} / \mathrm{kg}$ and $10 \mathrm{~g} / \mathrm{kg}$ EZSO significantly reduced the serum levels of TG by approximately $26 \%(p<$
$0.05)$ and $23 \%(p<0.05)$, TC by approximately $19 \%(p<0.01)$ and $13 \%(p<0.01)$, LDL-C by approximately $18 \%(p<0.05)$ and $21 \%(p<$ 0.01 ) in hyperlipidemic hamsters. SIM markedly elevated the serum level of HDL-C by approximately $67 \%(p<0.01)$ compared with HPL group. However, all the doses of EZSO did not show significant effect on the serum level of HDL-C (Table 1).

\section{Effects of EZSO on MDA and NO levels in serum}

Serum levels of MDA and NO in HPL group hamsters were significantly higher than Control group hamsters, as showed in Table 3 (both $p<$ $0.001)$. Doses of $5 \mathrm{~g} / \mathrm{kg}$ and $10 \mathrm{~g} / \mathrm{kg}$ EZSO significantly decreased the levels of MDA by approximately $16 \%(p<0.05)$ and $30 \%(p<$ $0.001)$, NO by approximately $15 \%(p<0.01)$ and $31 \%(p<0.001)$ (Table 2).

\section{Effects of EZSO on PPAR - expression and location in liver cells}

In the immunohistochemical assay, PPAR expression was significantly higher in the liver of the HPL group hamsters than that of Control group hamsters $(p<0.01)$, and PPAR - was detected both in the cytoplasm and nucleus. SIM markedly promoted the expression of PPAR - in the liver by approximately $200 \%$ compared with the HPL group $(p<0.01)$. Doses of $5 \mathrm{~g} / \mathrm{kg}$ and $10 \mathrm{~g} / \mathrm{kg}$ EZSO significantly increased the expression of PPAR - in the liver by approximately $101 \%(p<0.01)$ and $142 \%(p<$ 0.01) compared with the HPL group. Furthermore, in SIM, 5 and $10 \mathrm{~g} / \mathrm{kg}$ EZSO groups, more PPAR - was detected in the nucleus than in the cytoplasm (Figure 1).

\section{Effect of EZSO on PPAR - expression in liver tissues}

In Western blot assay, the PPAR - protein was significantly increased by approximately $120 \%$ in the liver tissues of the HPL group compared with the Normal group $(p<0.01)$. SIM markedly promoted the expression of PPAR - in the liver tissues by approximately $120 \%(p<0.01)$ compared with the HPL group. Doses of $5 \mathrm{~g} / \mathrm{kg}$ and $10 \mathrm{~g} / \mathrm{kg}$ EZSO significantly increased the expression of PPAR - in liver tissues by approximately $70 \%(p<0.05)$ and $100 \%(p<$ 0.01 ) compared with the HPL group (Figure 2). 
Table 1: Effect of EZSO on the serum levels of TG, TC, HDL-C and LDL-C in hyperlipidemic hamsters

\begin{tabular}{lccccc}
\hline Group & Dose & TG (mmol/L) & TC (mmol/L) & HDL-C (mmol/L) & LDL-C (mmol/L) \\
\hline Control & & $1.93 \pm 0.81$ & $1.98 \pm 0.43$ & $1.20 \pm 0.23$ & $0.93 \pm 0.32$ \\
HPL & & $7.60 \pm 2.53^{*}$ & $9.35 \pm 2.30^{*}$ & $2.54 \pm 0.41^{*}$ & $7.84 \pm 1.61^{*}$ \\
SIM & $4 \mathrm{mg} / \mathrm{kg}$ & $3.34 \pm 1.64^{\# \#}$ & $6.54 \pm 1.55^{\# \#}$ & $4.24 \pm 1.20^{\# \#}$ & $2.87 \pm 0.98^{\# \#}$ \\
EZSO & $2.5 \mathrm{~g} / \mathrm{kg}$ & $7.58 \pm 2.75$ & $8.67 \pm 2.44$ & $2.51 \pm 0.46$ & $7.67 \pm 2.21$ \\
& $5 \mathrm{~g} / \mathrm{kg}$ & $5.59 \pm 1.55^{\#}$ & $7.61 \pm 1.62^{\# \#}$ & $2.45 \pm 0.41$ & $6.45 \pm 1.58^{\#}$ \\
& $10 \mathrm{~g} / \mathrm{kg}$ & $5.87 \pm 1.45^{\#}$ & $8.11 \pm 0.97^{\# \#}$ & $2.54 \pm 0.70$ & $6.21 \pm 0.86^{\# \#}$
\end{tabular}

Data are presented as mean \pm SEM $(n=10) ;{ }^{*} p<0.001$ vs. Control group; ${ }^{\#} p<0.05,{ }^{\#} p<0.01$, vs. HPL group

Table 2: Effects of EZSO on serum levels of MDA and NO in hyperlipidemic hamsters

\begin{tabular}{lccc}
\hline Groups & Dose & MDA $(\boldsymbol{\mu m o l} / \mathrm{L})$ & NO $(\boldsymbol{\mu m o l} / \mathrm{L})$ \\
\hline Control & & $4.86 \pm 0.87$ & $11.31 \pm 2.97$ \\
HPL & $20.69 \pm 4.39^{*}$ & $62.87 \pm 7.11^{*}$ \\
SIM & $4 \mathrm{mg} / \mathrm{kg}$ & $9.65 \pm 1.35^{\# \#}$ & $21.27 \pm 5.19^{\# \#}$ \\
EZSO & $2.5 \mathrm{~g} / \mathrm{kg}$ & $19.80 \pm 3.32$ & $61.78 \pm 7.88$ \\
& $5 \mathrm{~g} / \mathrm{kg}$ & $17.37 \pm 2.36^{\#}$ & $53.46 \pm 6.25^{\# \#}$ \\
& $10 \mathrm{~g} / \mathrm{kg}$ & $14.41 \pm 2.64^{\# \#}$ & $44.06 \pm 6.48^{\# \#}$ \\
\hline
\end{tabular}

Data are presented as mean \pm SEM $(n=10) .{ }^{*} p<0.01$ vs. Control group; ${ }^{\#} p<0.05,{ }^{\#} p<0.01$, vs. HPL group
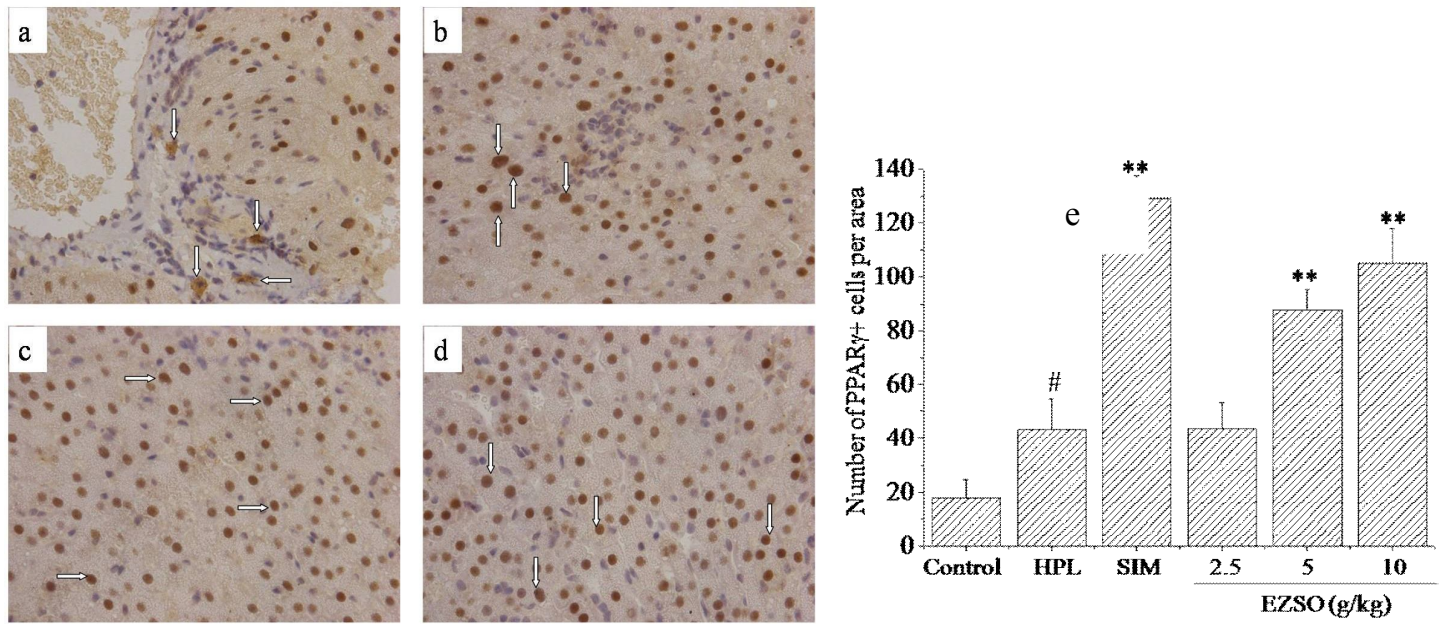

Fig 1: Effect of EZSO on PPAR - expression and location in the liver cells of hamsters by immunohistochemical assay. A: Expression and location of PPAR - protein in the liver cells of hamsters were analyzed by immunohistochemical assay. The results presented were representative of immunohistochemical analysis ( • 100). (a) HPL group; (b) SIM group; (c) $5 \mathrm{~g} / \mathrm{kg}$ EZSO; (d) $10 \mathrm{~g} / \mathrm{kg}$ EZSO, (e) Bar charts show quantitative evaluation of the number of PPAR $\cdot{ }^{+}$cells per area $(\cdot 100) .{ }^{*} p<0.01$ compared with Control group; ${ }^{* *} p<0.01$ compared with HPL group

\section{DISCUSSION}

The present study demonstrates that EZSO, which is rich in ALA, significantly decreases the levels of TG, TC and LDL-C in serum of HFDinduced hyperlipidemic hamsters. However, the hypotriglyceridemic and hypocholesterolemic effects were not dose-dependent. The mean TG and TC concentrations of hamsters treated with 5 $\mathrm{g} / \mathrm{kg}$ EZSO were similar to those of $10 \mathrm{~g} / \mathrm{kg}$
EZSO. This data implies that the low dose of EZSO may provide cardioprotective effects similar to that of higher doses in this animal model.

In this study we used the hamsters to evaluate the effects of EZSO on levels of serum lipids. Previous studies have used rats for the research of hypolipidemic agents. However, rats may not 

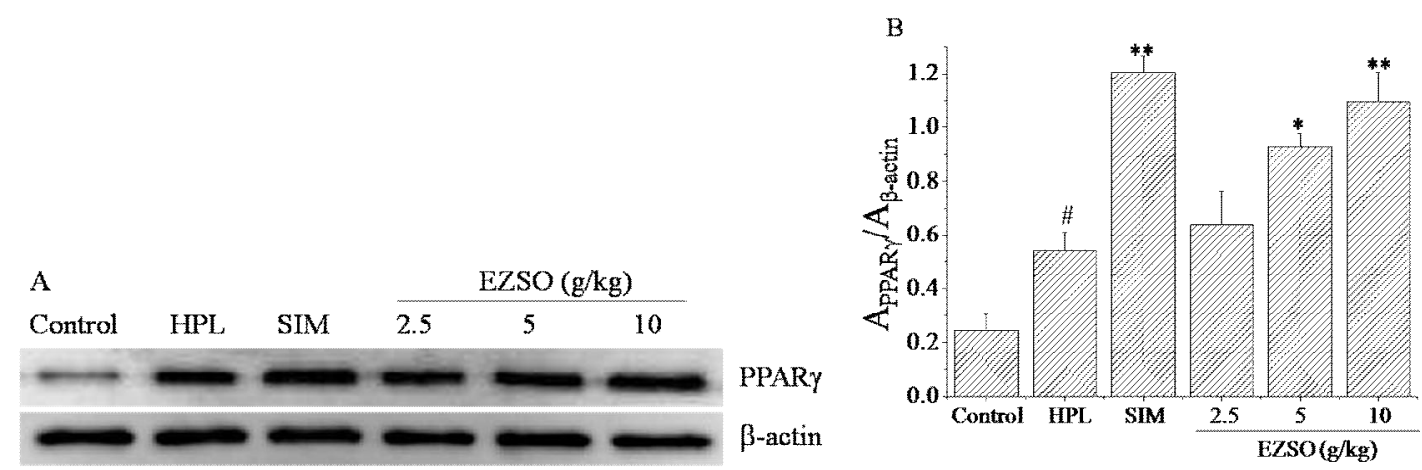

Fig 2: Effect of EZSO on PPAR? expression in the liver tissues of hamsters. A: Expression of PPAR日 protein in the liver tissues of hamsters was analyzed by Western blot assay. $\beta$-actin is used as loading control. The result presented was representative of four independent experiments; B: Bar charts show quantitative evaluation of PPAR? bands by densitometry from four independent experiments; ${ }^{*} p<0.01$ compared with Control group; ${ }^{*} p<$ $0.05,{ }^{* *} p<0.01$ compared with HPL group

be a good model for lipid studies as they are associated with some inherent deficiencies including high HDL to LDL ratios, lack of gallbladders, require high cholesterol diets with supplemental bile acids and thiouracil to develop hypercholesterolemia, and the organ contribution of cholesterol synthesis varies significantly from humans [10]. The plasma lipoprotein profile, bile acid pool composition, and metabolic responses to changes in dietary cholesterol make the hamsters much more comparable to humans. Hence, hamsters represent a better animal model for the evaluation of lipid-lowing agents [11]. In this study we found that TG, TC, HDL-C and LDL-C in hamster serum increased about 4-, 5-, 2- and 8-fold, respectively, after continuous feeding with HFD for 30 days. These results suggest that hamsters are a good animal model for hyperlipidemia.

The cardioprotective action of $n-3$ PUFAs have been demonstrated by studies of animal models and human trails [3]. EZSO is rich in ALA, where, ALA may be the main component of EZSO responsible for its hypolipidemic effect. Much evidence support a role for ALA and its metabolic products in improving many cardiovascular risk factors including TG, TC and LDL-C in both animals and humans, reducing the risk of $\mathrm{CHD}$ $[12,13]$. It has been reported that in rats, flaxseed, which is rich in ALA, reduced plasma TC, TG and LDL-C by $33 \%, 23 \%$ and $67 \%$, respectively [14]. Study showed that ALA might alter serum lipid concentrations when fed at physiologically relevant concentrations [15]. A study in Costa Rica found that high adipose tissue ALA content was associated with a lower risk of non-fatal acute myocardial infarction, which suggested that consumption of vegetable oils rich in ALA confers protection against cardiovascular disease [16].
However, some researchers arrived at different conclusions. In a 12-week trial involving 86 healthy Canadian men and women, flaxseed oil (ALA dose $1 \mathrm{~g} / \mathrm{d}$ ) had no effects on levels of serum TC, TG, LDL-C, HDL-C, LDL oxidation, platelet aggregation, or inflammatory markers [17]. In another randomized trial in 62 healthy men in the United States, flax oil (ALA doses of $1.2,2.4$, or $3.6 \mathrm{~g} / \mathrm{d}$ ), did not alter plasma TC, TG, HDL-C [18]. Much of the data variability on serum lipids in human or animal studies is attributed to complex contributions of dietary cholesterol, fat and other compositions of the diet, animal gender, drug dosage, medication time, route of administration and human or animal genetic background. To minimize the effect of these confounders in this study, only hamsters with the same age, sex and weight were used, and hamsters were not administered by the admixture with diets and drugs which may cause the dosage inconsistent, but by gastric lavage daily, and simvastatin, a widely used hypolipidemic drug in clinical practice, was used as a positive control drug. We found in this study that EZSO markedly reduced the levels of TG by $26 \%$, TC by $19 \%$ and LDL-C by $18 \%$ in serum of hyperlipidemic hamsters. Although the hypolipidemic efficiency of EZSO was less than that of simvastatin, these data indicated that EZSO might improve the cardiovascular risk markers. Interestedly, we found that EZSO did not statistically change the content of serum $\mathrm{HDL}-\mathrm{C}$ in hyperlipidemic hamsters. Morise et al reported that ALA (linseed oil) were not significantly decreased the serum HDL-C in hyperlipidemic hamsters [19], which was consistent with our experimental results.

Since currently the protection against CVD of ALA has been identified and the lipid-lowering results are not consistent, other underlying 
mechanisms may be associated with the cardiovascular protective effects of ALA. Oxidative stress is involved in the pathogenesis of CHD. Excess oxidative stress is caused by an imbalance between pro- and anti-oxidants, leading to an overproduction of free radicals, which may damage cellular components and functions. Hypertriglyceridemia or hypercholesterolemia may increase activity of the oxidant producing enzymes to induce the overproduction of free radicals and NO, which may damage the vascular structure and functions [20]. In this study, we found that EZSO decreased the contents of two markers of oxidative stress in hyperlipidemia in a dose-dependent manner, suggesting that anti-oxidative stress might be involved in the cardioprotective action of EZSO.

PPARy is a member of the nuclear hormone receptor super family, which forms heterodimers with the retinoid $X$ receptor. After the nuclear translocation, PPARY regulates genes expression by binding to a PPAR-responsive element (PPRE) in the promoter region of a variety of target gene [6]. Activation of the PPARY can improve insulin sensitivity and reduce hyperlipidemia, hyperglycemia and inflammation [7]. In this study, we found that EZSO increased the expression of PPARY in a dose-dependent manner using immunohistochemical assay and Western blot assay. We also found that more PPARy was detected in the nucleus than in the cytoplasm after EZSO treatment. These results suggest that EZSO may induce the nuclear translocation and transcriptional activation of PPARY.

\section{CONCLUSION}

In this study, we found that EZSO significantly decreased the levels of TG, TC, LDL-C, NO and MDA in serum of hyperlipidemic hamsters. This indicates that EZSO shows potential hypolipidemic and anti-oxidative effects in hyperlipidemic hamsters. These findings suggest that EZSO would be a promising candidate as a novel hypolipidemic health product.

\section{ACKNOWLEDGEMENT}

This work was supported by grants from Chongqing Science and Technology Commission (CSTC, 2011AB5007) and Innovative Research Team Development Program in Universities of Chongqing (KJTD 201314, KJTD201020).

\section{REFERENCES}

1. Erkkila AT, Lehto S, Pyorala K, Uusitupa MI. n-3 Fatty acids and 5-y risks of death and cardiovascular disease events in patients with coronary artery disease. Am J Clin Nutr 2003; 78: 65-71.

2. Grimsgaard S, Bonaa KH, Hansen JB, Nordoy A. Highly purified eicosapentaenoic acid and docosahexaenoic acid in humans have similar triacylglycerol-lowering effects but divergent effects on serum fatty acids. Am J Clin Nutr 1997; 66: 649-659.

3. Swanson $D$, Block $R$, Mousa SA. Omega-3 fatty acids EPA and DHA: health benefits throughout life. Adv Nutr 2012; 3: 1-7

4. de Lorgeril M, Salen P, Martin JL, Monjaud I, Delaye J, Mamelle N. Mediterranean diet, traditional risk factors, and the rate of cardiovascular complications after myocardial infarction: final report of the Lyon Diet Heart Study. Circulation 1999; 99: 779-785.

5. Bemelmans WJ, Broer J, Feskens EJ, Smit AJ, Muskiet FA, Lefrandt JD, Bom VJ, May JF, Meyboom-de Jong $B$. Effect of an increased intake of alpha-linolenic acid and group nutritional education on cardiovascular risk factors: the Mediterranean Alpha-linolenic Enriched Groningen Dietary Intervention (MARGARIN) study. Am J Clin Nutr 2002; 75: 221-227.

6. Robinson E, Grieve DJ. Significance of peroxisome proliferator-activated receptors in the cardiovascular system in health and disease. Pharmacol Ther 2009; 122: 246-263.

7. Xu HE, Lambert MH, Montana VG, Parks DJ, Blanchard SG, Brown PJ, Sternbach DD, Lehmann JM, Wisely GB, Willson TM, Kliewer SA, Milburn MV. Molecular recognition of fatty acids by peroxisome proliferatoractivated receptors. Mol Cell 1999; 3: 397-403.

8. Lucas EA, Lightfoot $S A$, Hammond LJ, Devareddy L, Khalil DA, Daggy BP, Smith BJ, Westcott N, Mocanu $V$, Soung $D Y$, Arjmandi $B H$. Flaxseed reduces plasma cholesterol and atherosclerotic lesion formation in ovariectomized Golden Syrian hamsters. Atherosclerosis 2004; 173: 223-229.

9. Zheng $X X$, Yin ZY, Du RY, Fang MJ, Wang XM, Li Q. Extraction of crust oil and kernel oil from pepper seeds by two-step extraction technology. Food Sci 2010; 31: 180-184.

10. Harris WS. $n-3$ fatty acids and serum lipoproteins: animal studies. Am J Clin Nutr 1997; 65: 1611S-1616S.

11. Nistor A, Bulla A, Filip DA, Radu A. The hyperlipidemic hamster as a model of experimental atherosclerosis. Atherosclerosis 1987; 68: 159-73.

12. Mantzioris E, James MJ, Gibson RA, Cleland LG. Dietary substitution with an alpha-linolenic acid-rich vegetable oil increases eicosapentaenoic acid concentrations in tissues. Am J Clin Nutr 1994; 59: 1304-1309.

13. Egert S, Kannenberg F, Somoza V, Erbersdobler HF, Wahrburg U. Dietary alpha-linolenic acid, EPA, and $D H A$ have differential effects on $L D L$ fatty acid

Trop J Pharm Res, November 2014; 13(11):1842 
composition but similar effects on serum lipid profiles in normolipidemic humans. J Nutr 2009; 139: 861868.

14. Ratnayake WMN, Behrens WA, Fischer PWF, L'Abbé M, Mongeau R, Beare-Rogers JL. Chemical and nutritional studies of flaxseed (variety Linott) in rats. $J$ Nutr Biochem 1992; 3: 232-240.

15. Bierenbaum ML, Reichstein R, Watkins TR. Reducing atherogenic risk in hyperlipemic humans with flax seed supplementation: a preliminary report. J Am Coll Nutr 1993; 12: 501-504

16. Baylin A, Kabagambe EK, Ascherio A, Spiegelman D, Campos $H$. Adipose tissue alpha-linolenic acid and nonfatal acute myocardial infarction in Costa Rica. Circulation 2003; 107: 1586-1591.

17. Kaul N, Kreml R, Austria JA, Richard MN, Edel AL, Dibrov E, Hirono $S$, Zettler ME, Pierce GN. A comparison of fish oil, flaxseed oil and hempseed oil supplementation on selected parameters of cardiovascular health in healthy volunteers. J Am Coll Nutr 2008; 27: 51-58.

18. Barcelo-Coblijn G, Murphy EJ, Othman R, Moghadasian $\mathrm{MH}$, Kashour T, Friel JK. Flaxseed oil and fish-oil capsule consumption alters human red blood cell $n-3$ fatty acid composition: a multiple-dosing trial comparing 2 sources of $n-3$ fatty acid. Am J Clin Nutr 2008; 88: 801-809.

19. Morise A, Combe $N$, Boue C, Legrand P, Catheline D, Delplanque $B$, Fenart E, Weill $P$, Hermier D. Dose effect of alpha-linolenic acid on PUFA conversion, bioavailability, and storage in the hamster. Lipids 2004; 39: 325-334.

20. Münzel T1, Gori T, Bruno RM, Taddei S. Is oxidative stress a therapeutic target in cardiovascular disease? Eur Heart J 2010; 31: 2741-2748. 